\title{
EM BUSCA DA EFICIÊNCIA NO TRANSPORTE TERCEIRIZADO: ESTRUTURA DE CUSTOS, PARCERIAS E ELIMINAÇÃO DE DESPERDÍCIOS
}

\section{GESTÃO $\&$ PRODUÇÃO}

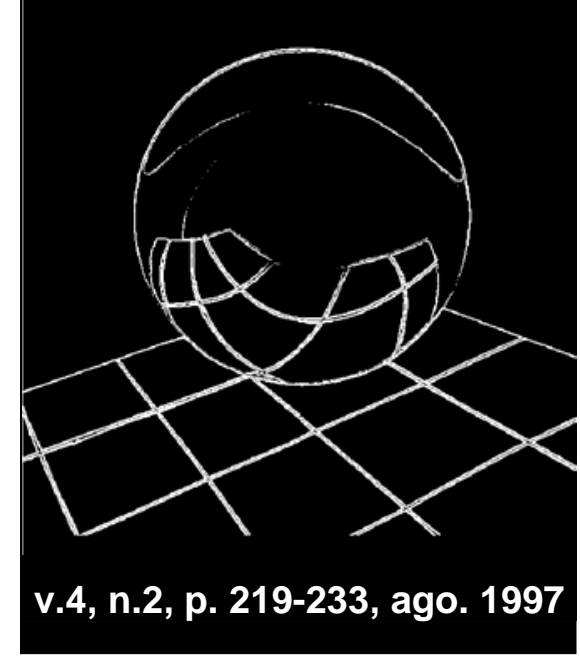

Paulo Fernando Fleury

Professor Titular - Cátedra Ipiranga de Estratégia de Operações - COPPEAD/UFRJ

Marcos Gonçalves Avila Professor - COPPEAD/UFRJ

Peter Wanke Pesquisador - Centro de Estudos em Logística COPPEAD/UFRJ COPPEAD/UFRJ - Ed. do COPPEAD Cd. Universitária II. do Fundão Rio de Janeiro - RJ - Cep. 21949-900 e-mail:cel@.coppead.ufrj.br

\section{Resumo}

O objetivo deste artigo é apresentar um modelo racional para custeio de transporte como elemento fundamental ao bom funcionamento de parcerias entre embarcadores e transportadoras numa cadeia de suprimentos. A aplicação deste modelo a situações reais traz à tona uma série de informações importantes, a principal delas é o fato que o atual sistema de custeio utilizado pela maioria das empresas brasileiras causa sérias distorções em termos de custos, quando se consideram rotas curtas e rotas longas, subavaliando as primeiras e superavaliando as últimas. Estas distorções estão vinculadas à elevada ineficiência no transporte de mercadorias, sobretudo nas operações de carregamento e descarregamento, cujos tempos médios excedem seis horas. Dentro deste escopo são definidos o conceito de parceria, suas implicações organizacionais e suas conseqüencias imediatas, como por exemplo, o envolvimento de ambas as partes num programa de qualidade e produtividade do transporte. A adoção deste programa, paralelamente ao acordo quanto a um sistema de custeio de frete com as transportadoras que garantam um nível mínimo de retorno sobre seu investimento, tornam mais claras, e facilmente mensuráveis, as oportunidades para exploração de ganhos conjuntos dentro de um ambiente de parceria. Finalmente, são descritas as três causas básicas que levam a ineficiência das operações de carregamento e descarregamento no Brasil: organizacionais, tecnológicas e procedimentos. 


\section{Introdução}

A atividade de transporte representa o elemento mais visível e importante do custo logístico na maior parte das empresas. O frete costuma absorver aproximadamente $60 \%$ do gasto logístico e entre 9 e $10 \%$ do produto nacional bruto para a economia de uma nação relativamente desenvolvida (BALLOU, 1993). Entretanto, no Brasil pouca importância é atribuída ao gerenciamento das atividades de transporte, contrariamente ao que acontece nos EUA, onde a perspectiva para contratação desses serviços mudou de uma lógica baseada simplesmente em preços para uma outra que busca a eficiência e a qualidade com base num relacionamento de parceria (GIBSON, 1993). Estas relações de parceria geralmente resultam num comprometimento de longo prazo, em que as transportadoras e suas empresas contratantes tornam-se interdependentes em operações, rentabilidade e até mesmo com relação a sua sobrevivência.

Levantamentos realizados pelo Centro de Estudos em Logística (COPPEAD/UFRJ) em diversas empresas brasileiras determinaram um elevado padrão de ineficiência no transporte, sobretudo nas atividades de carregamento e descarregamento, em que os tempos de espera geralmente ultrapassam seis horas. Por outro lado, um grande número de transportadoras mensura seus custos de frete com base em uma metodologia que aloca os custos fixos a cada rota em proporção a quilometragem percorrida. Estes métodos de custeio criam distorções nos resultados; especificamente, rotas longas absorvem um custo maior do que deveriam absorver e as rotas curtas um custo menor do que deveriam absorver (isto é, há um subsídio cruzado em que as rotas longas subsidiam as rotas curtas). A distorção existe porque o custo de cada rota depende de forma significativa, como será indicado adiante, dos custos das atividades de carregamento e descarregamento, que são função do tempo que estas atividades consomem e não da quilometragem percorrida.

As conseqüências destas distorções podem ser desastrosas na medida que inviabilizam um processo de negociação de preços baseado no grau de eficiência do uso dos recursos (redução de desperdícios) e contribuem para manutenção de práticas tradicionais de negociações de preço, baseadas na quilometragem e, por ocasião de reajustes, nas variações nos preços dos insumos. O subsídio cruzado entre rotas implica em preços baixos para rotas curtas e preços altos para rotas longas. Como rotas curtas custam na verdade mais do que o sistema tradicional de custeio (que aloca pela quilometragem) indica, elas serão pouco lucrativas, ocorrendo com as rotas longas exatamente o contrário. Esta situação faz com que a gerência de muitas transportadoras não utilize os tradicionais sistemas de custeio como ferramenta de apoio à tomada de decisão, tornando-os cada vez mais desacreditados.

Este artigo tem por objetivo abordar o desenvolvimento de um sistema racional de custeio de fretes, dentro do conceito de parcerias entre empresas, cuja vantagem é a de identificar e mensurar possíveis ganhos de produtividade no transporte, permitindo negociações de preços baseados na eficiência do uso e não no preço de recursos. 


\section{Parcerias Logísticas - Mudando a Perspectiva Gerencial}

$\mathrm{D}$ urante a década de 80, inúmeras transformações afetaram o relacionamento existente entre as diversas organizações que operam dentro de uma mesma cadeia de valor agregado. A dramática reestruturação das corporações em busca de maiores níveis de qualidade e produtividade, a globalização dos mercados e o surgimento de novas tecnologias de processamento e transmissão de dados desempenharam e vêm desempenhando um papel chave na mudança das práticas tradicionais de negócios entre empresas. A penetração cada vez mais rápida em novos mercados ou a consolidação do marketshare já existente passam muitas vezes pela adoção de novas estratégias para gestão da distribuição na cadeia de suprimentos. É dentro deste contexto que deve ser entendido o estabelecimento de parcerias (alianças logísticas) de uma empresa com seus transportadores.

Segundo BOWERSOX (1990), o relacionamento tradicional existente entre uma empresa e suas transportadoras é antagônico e adversário, isto é, um jogo do tipo "perdeganha” em que cada uma das partes está buscando sempre aumentar sua margem no negócio em detrimento da outra. Em geral, as empresas contratantes barganham tabelas de preços de frete em função de seu poder econômico. Conseqüentemente o compartilhamento de informações e o planejamento de diversas atividades logísticas, como por exemplo, programação de entregas, carregamento no embarcador e descarregamento nos clientes finais são mínimos ou quase que inexistentes.

Para que haja a implementação de parcerias logísticas efetivas entre uma empresa e seus transportadores é necessário o estabelecimento de um ambiente de confiança mútua entre as partes. Não é tarefa fácil, visto que inúmeras barreiras culturais dentro e fora da organização devem ser vencidas. LA LONDE (1989) propõe uma filosofia de gestão logística capaz de enxergar os principais ganhos decorrentes de uma nova relação empresa-transportadoras, ou seja, a criação de uma interface coordenada, eficiente e previsível com seus clientes. Para as transportadoras, por sua vez, a contrapartida se encontra numa maior previsibilidade em relação à capacidade adequada (dimensionamento de frota), ao seu horizonte de investimento e à oportunidade de aprimorar suas práticas operacionais com seus demais parceiros (diferenciação). Finalmente, GARDNER (1994) ressalta que o estabelecimento de relações de parceria, e conseqüentemente da nova filosofia de gestão proposta por LA LONDE, é facilitado quando se limita o número de parceiros transportadores, possibilitando maior controle sobre o serviço fornecido, ao ser garantido em contrapartida um maior e mais seguro volume de frete no longo prazo.

Diversos autores como GARDNER e GIBSON, citados anteriormente, levantaram os principais critérios à seleção de transportadoras para desenvolvimento de parcerias. Entretanto, LA LONDE melhor sintetizou os principais fatores organizacionais ao estabelecimento de uma parceria empresatransportador, quaisquer que sejam os objetivos e a perspectiva de duração deste relacionamento. Se não vejamos:

\section{Ambos os parceiros devem ganhar com a relação}

Empresas que buscam construir alianças bem sucedidas devem estruturar um relacionamento do tipo ganha-ganha com base na exploração conjunta das oportunidades de aumento de eficiência existentes na interface do canal. A divisão dos ganhos obtidos com a redução dos desperdícios nas atividades de transporte é função da responsabilidade que cada 
empresa envolvida possui sobre determinada etapa (carregamento, descarregamento ou transporte), e não mais de pressões econômicas.

\section{Visão estratégica e objetivos comuns}

A parceria, por ser um tipo de relacionamento essencialmente de longo prazo, envolve a determinação de expectativas estratégicas e padrões comuns de desempenho inerentes às atividades de transporte (janelas de tempo, tempos médios e limites para carregamento, descarregamento e viagens, etc), bem como de diversas outras características que determinam a qualidade no serviço de transporte prestado. PARASURAMAN (1988) definiu qualidade no serviço de transporte como entender o grau de discrepância existente entre as expectativas ou desejos das empresas contratantes com relação ao serviço prestado e suas percepções sobre o serviço que está sendo realmente prestado. Posteriormente, HOPKINS (1993) descreveu um elenco não exaustivo de dimensões relevantes à qualidade no transporte, o qual inclui: veículos com boa aparência, segurança no transporte de carga, entregas na hora combinada, etc.

\section{Grau de aproximação entre as duas} organizações

É o mais importante elemento para o sucesso de uma parceria embarcadortransportador, constituindo-se muitas vezes de diversas visitas às instalações da empresa parceira com a finalidade de uma melhor compreensão de ambas operações. KANTER (1994) sugere que um sistema de parceria não pode pura e simplesmente ser controlado por contratos ou acordos formais, mas deve proporcionar a criação de uma infra-estrutura adequada que amplie as perspectivas quanto à atividade de transporte. A partir daí, é possível identificar claramente diversas oportunidades para eliminação de ineficiências, bem como estabelecer um canal de comunicação informal e extra-organizacional capaz de flexibilizar e agilizar o processo de tomada de decisões, sejam elas estratégicas (dimensionamento de frota) ou operacionais (programação de veículos).

\section{Compartilhamento de informações}

Conforme dito anteriormente, deve predominar um ambiente de confiança mútua numa relação de parceria, de modo a proporcionar um intercâmbio aberto de informações entre ambas as partes. Estas informações devem (além de ter um caráter estritamente operacional sobre como é feito e como são consumidos os recursos necessários ao transporte de um elo para outro na cadeia de suprimentos) ser relevantes para a determinação de quão produtiva ou eficiente é cada etapa da atividade de transporte (LANDEROS, 1995).

Monitorar o desempenho da atividade de transporte passa necessariamente pelo controle e acompanhamento do tempo de permanência no fornecedor para carregamento, do tempo de permanência no cliente para descarregamento e dos tempos de viagem entre cliente-fornecedor. Entretanto, a experiência em diversas empresas brasileiras que operam no eixo RJ-SP-MG, mostra que além de não haver uma verificação sistemática destes tempos por parte dos departamentos funcionais responsáveis pelo processo logístico, as etapas de carregamento e descarregamento no cliente são extremamente demoradas, confusas, pouco padronizadas e mal coordenadas.

O desinteresse pelo monitoramento dos tempos de carregamento, descarregamento e viagem pode ser muitas vezes explicado pelo fato dos responsáveis pelo gerenciamento logístico não os entenderem como uma parcela significativa dos custos de frete, e desta forma não direcionarem esforços no sentido de sua redução. Já os 
elevados tempos de permanência em fornecedores e clientes são muitas vezes causados por métodos burocráticos ineficientes de controle e processamento de informações relevantes às atividades de carregamento e descarregamento, por um gerenciamento interno de tráfego ineficaz, etc.

O que faz com que, num sistema de parceria embarcador-transportador, informações tão sensíveis sejam trocadas? A resposta é simples. O sistema só funciona pela existência de uma estrutura racional de determinação de custos, preços e lucros. Tal estrutura faz com que ambas as partes queiram trabalhar conjuntamente para benefício mútuo, em vez de suspeitarem uma da outra. Seus esforços são canalizados para objetivos mutuamente benéficos, como por exemplo, redução dos tempos de carregamento e descarregamento obtida com o reprojeto das atividades de recepção e expedição de produtos, envolvendo, conforme visto anteriormente, maior coordenação (fluxo de informações) entre as partes envolvidas.

A seguir abordaremos em maiores detalhes por que um sistema de custeio adequado contém as características descritas no item anterior, e como estas podem ser utilizadas como ferramenta de auxílio ao planejamento, execução e controle de um programa de aumento de produtividade e qualidade no transporte.

\section{Entendendo os Custos de Transporte com Base em suas Etapas Principais}

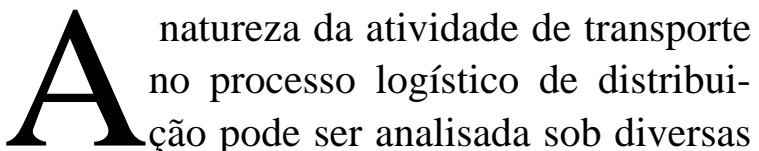
perspectivas. Esta atividade integra o sistema logístico, aproximando fornecedores e clientes geograficamente isolados e pode ser entendida como uma ferramenta poderosa na redução dos custos totais de uma cadeia de suprimentos (BOWERSOX, 1996). O entendimento da estrutura de custos do transporte, conforme visto anteriormente, é portanto fundamental para permitir, dentro do contexto de parceria, o desenvolvimento de estratégias de seleção de transportadoras focadas na melhoria contínua de suas operações. Segundo GIBSON (1993), um número cada vez maior de empresas está percebendo que a adoção de estratégias de contratação com base exclusivamente no preço do frete quase sempre resulta em diversos problemas como congestionamento nas docas de carregamento e descarregamento, problemas administrativos com relação à coordenação de carregamentos, etc.

Apesar de demandar um enorme esforço entre embarcador e transportadores com relação à coordenação diária de sua programação de entregas com os tempos de carregamento, viagem e descarregamento e suas respectivas janelas de tempo, a atividade de transporte pode ser representada de forma simplificada, conforme a figura 1 , por quatro etapas principais: carregamento na empresa, viagem da empresa ao cliente, descarregamento no cliente e retorno à empresa. 


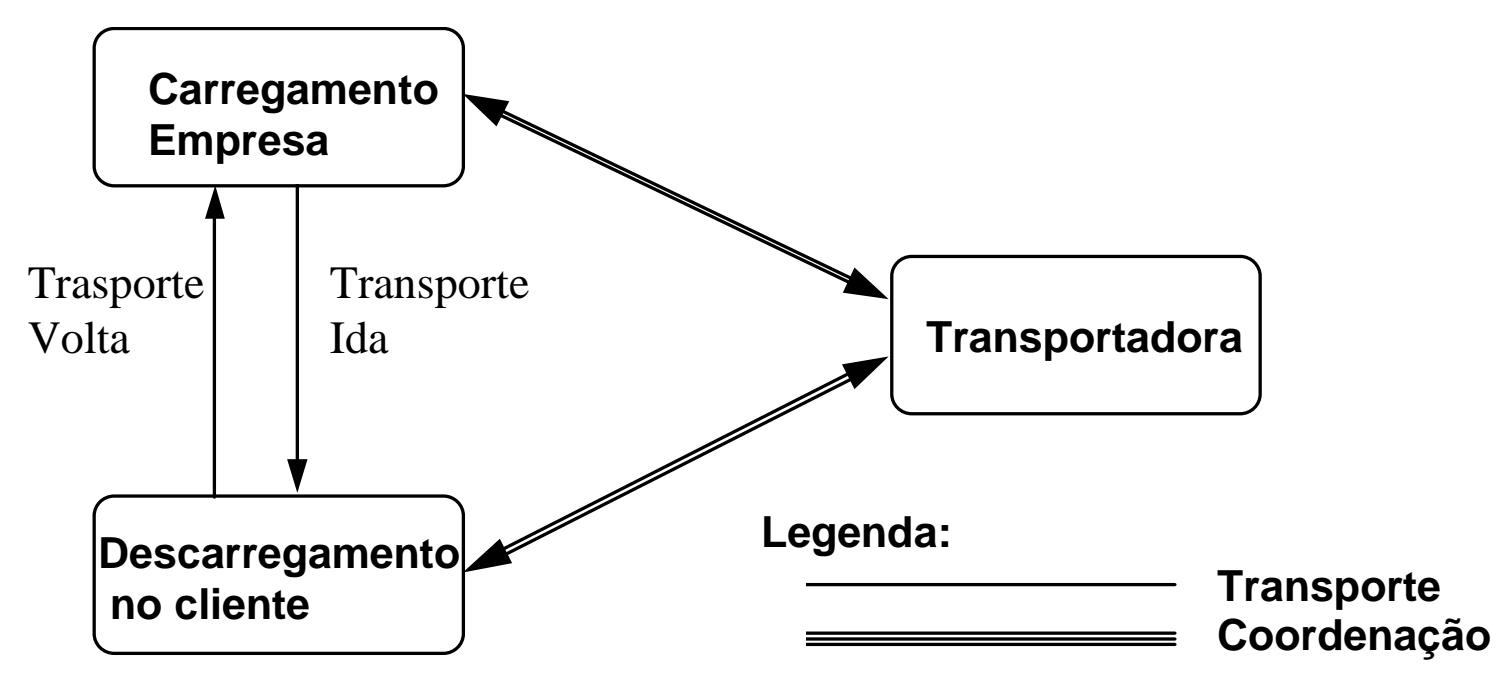

Figura 1 - Fluxo de atividades no transporte de carga

$\mathrm{Na}$ análise que se segue, assumimos um cenário com as seguintes premissas básicas (os demais parâmetros assumidos no trabalho serão discutidos adiante):

Transporte rodoviário de caminhão feito com exclusividade ao cliente contratante do serviço, isto é, o caminhão após a atividade de descarregamento volta vazio ao ponto de origem.

Um único produto é transportado e não existe ponto intermediário de carregamento e descarregamento ao longo do percurso.

Os custos da empresa transportadora podem ser classificados em fixos e variáveis, assumindo-se como nível de atividade da empresa a quilometragem percorrida. Os custos fixos agregam duas parcelas: os fixos de operação do caminhão e os fixos de administração (coordenação) da sede. Os custos fixos de operação decorrem em grande parte de decisões tomadas quanto a capacidade instalada de transporte.

O objeto de custo em questão é uma rota, isto é, o conjunto das etapas de carregamento, viagem de ida e volta e descarregamento para servir um determinado cliente em determinado percurso, conforme visto anteriormente. Para o custeio de cada rota é necessário definir bases de alocação tanto para os custos fixos de operação quanto para os custos fixos de administração da sede. A discussão a seguir especifica os parâmetros utilizados neste trabalho.

Custos fixos de operação: estes custos representam recursos de capacidade e definem uma disponibilidade de tempo de equipamento e pessoas para operação das diversas rotas. Logo, cada rota deve pagar uma parcela destes custos em função do tempo de utilização destes recursos. Para fins de definição do número de horas pelo qual o total de custos fixos será dividido para que se chegue ao custo unitário de uso da capacidade, a proposta deste artigo é que se use uma medida de capacidade de operação (Para uma discussão e análise das diversas alternativas quanto a medida do volume do denominador, veja COOPER \& KAPLAN, 1991). Adotamos, portanto, como medida de capacidade de cada caminhão o total de horas de trabalho de um motorista em um turno.

Custos fixos de administração da sede: estes custos definem uma capacidade de apoio da administração. O fator causal do montante do trabalho de apoio foi avaliado como sendo o número de conhecimento de fretes emitidos. 
Calcular o custo do frete com base nos tempos de viagem, carregamento e descarregamento é condizente com os princípios do Custeio Baseado em Atividades (ABC) ao transporte. Dentre os principais benefícios citados por ELLRAM (1994), destacamos uma melhor compreensão da origem e volume de recursos consumidos por rota e um melhor discernimento quanto ao grau de utilização da frota e suas ineficiências. Contrariamente à prática gerencial brasileira, em que o custo do frete é função da capacidade de transporte, calculada com base na quilometragem das rotas e no número esperado de viagens no mês em cada rota, o sistema ABC o considera como função da capacidade total, medida em horas, que uma transportadora coloca à disposição de seus parceiros num determinado período.

Percebe-se, portanto, que as informações relativas aos custos de cada uma dessas principais etapas constituem um importante instrumento para monitoramento de desempenho e uma clara e inequívoca medição das oportunidades de ganhos que podem ser exploradas no elo embarcadortransportadora-cliente, com a redução dos desperdícios nas atividades de transporte.

\section{Uma Aplicação da Metodologia em Casos Específicos}

partir desta discussão, o custo total
de cada rota (CTR) pode ser
descrito como o somatório de três parcelas, como se segue:

A primeira parcela é o produto do custo fixo unitário de operação (CFUOp), em $\mathrm{R}$ \$hora, pelo somatório dos tempos de carregamento (TC), viagem (D/Vm) e descarregamento (TD) medidos em horas. Conforme indicado anteriormente, o custo fixo unitário de operação (CFUOp) é o custo fixo total divido por uma medida de capacidade de operação do caminhão, geralmente medida em horas.

\section{CFUOp $*[\mathrm{D} / \mathrm{Vm}+\mathrm{TC}+\mathrm{TD}]$}

Na equação acima, consideramos o tempo de viagem como razão entre a distância de ida e volta (D), medida em quilômetros, pela velocidade média da rota $(\mathrm{Vm})$ medida em $\mathrm{Km} / \mathrm{h}$.

A segunda é o produto do custo variável unitário (CVU), em $\mathrm{R} \$ / \mathrm{Km}$, pela distância percorrida $\mathrm{D}$, medida em quilômetros:

\section{CVU * D}

A terceira parcela, finalmente, corresponde ao produto do custo fixo unitário de administração (CFUAd), expressa em $\mathrm{R} \$$ /número de conhecimentos de frete, pelo número de conhecimentos de frete para determinada rota (NCF):

\section{CFUAd * NCF}

Desta forma, o somatório das três parcelas, isto é, o custo total de uma viagem para dada rota (CTR) é:

$$
\begin{array}{r}
\mathrm{CTR}=\mathrm{CFUOp} *[\mathrm{D} / \mathrm{Vm}+\mathrm{TC}+\mathrm{TD}]+ \\
+\mathrm{CVU} * \mathrm{D}+\mathrm{CFUAd} * \mathrm{NCF}
\end{array}
$$

Devemos ressaltar que os custos fixos unitários de operação incluem os itens de depreciação para cavalo e baú, salários e encargos sociais de motorista e mecânico, seguros e demais taxas em geral, bem como despesas gerais de viagem que incluem refeições e lanches do motorista. Estamos assumindo um caminhão Mercedes-Benz modelo MBL 1625, base de depreciação 48 meses e percentual residual de $50 \%$ do valor inicial do veículo. O baú é do tipo Antonini, base de depreciação de 72 meses e percen- 
tual residual de 50\% de seu valor inicial. Já os custos variáveis unitários incluem gastos com combustível, pneus, lavagens, peças de reposição e óleos lubrificantes. A partir dos valores-padrão verificados na indústria para os itens descritos acima, os custos foram calculados, chegando-se a seguinte equação:

$$
\begin{array}{r}
\mathrm{CTR}=25,0 *[\mathrm{D} / \mathrm{Vm}+\mathrm{TC}+\mathrm{TD}]+ \\
+0,35 * \mathrm{D}
\end{array}
$$

Antes de prosseguirmos, façamos algumas observações: o coeficiente 0,35 está em $\mathrm{R} \$ / \mathrm{Km}$ e refere-se aos custos variáveis unitários, o coeficiente 25,00 está em $\mathrm{R} \$$ /hora e refere-se aos custos fixos unitários de operação e o custo fixo de administração para apenas um conhecimento de carga é suficientemente pequeno para que possamos excluí-lo da última equação.

Conforme veremos a seguir, por meio de inúmeras simulações do tipo what-if, é possível determinar:

a participação percentual do tempo de carregamento e descarregamento sobre o custo total;

o impacto da redução do tempo de carregamento e descarregamento sobre o custo do frete;

a sensibilidade do custo de frete a variações no tempo de carregamento e descarregamento.

\subsection{Quantificação dos Ganhos Potenciais}

Recentes levantamentos conduzidos pelo Centro de Estudos em Logística (COPPEAD/UFRJ) junto a empresas brasileiras do setor de transporte de cargas, atacado, varejo, alimentos e petróleo revelou que, independentemente da distância da rota, seja ela curta, média ou longa, o tempo médio de carregamento e descarregamento é da ordem de seis horas. Devemos ressaltar que estes tempos não incluem somente a operação em si, mas também o tempo gasto com esperas por romaneios, filas, ordens de carregamento, etc.

Também foram levantadas as distâncias médias das rotas nessas empresas, situandose em torno de $500 \mathrm{Km}$, bem como as respectivas velocidades médias, na faixa de $50 \mathrm{Km} / \mathrm{h}$. Percebe-se facilmente que uma viagem de 10 horas, se considerando esta distância e velocidade média, tem seu tempo acrescido em $60 \%$ por conta de ineficiências no carregamento e descarregamento (tempo médio de 6 horas).

Rotas mais curtas, entretanto, são extremamente penalizadas. Uma rota de $100 \mathrm{Km}$, por exemplo, a uma velocidade média de 50 $\mathrm{Km} / \mathrm{h}$, apesar de concluída em 2 horas, seria acrescida de mais 6 horas, em média, para carregamento e descarregamento, totalizando um aumento de 300\%. Rotas mais longas, por sua vez, da ordem de $1000 \mathrm{Km}$, seriam percorridas em 20 horas (incluídos aí períodos para descanso do motorista) e sofreriam um acréscimo de apenas 30\%. A figura 2 a seguir ilustra o problema: 


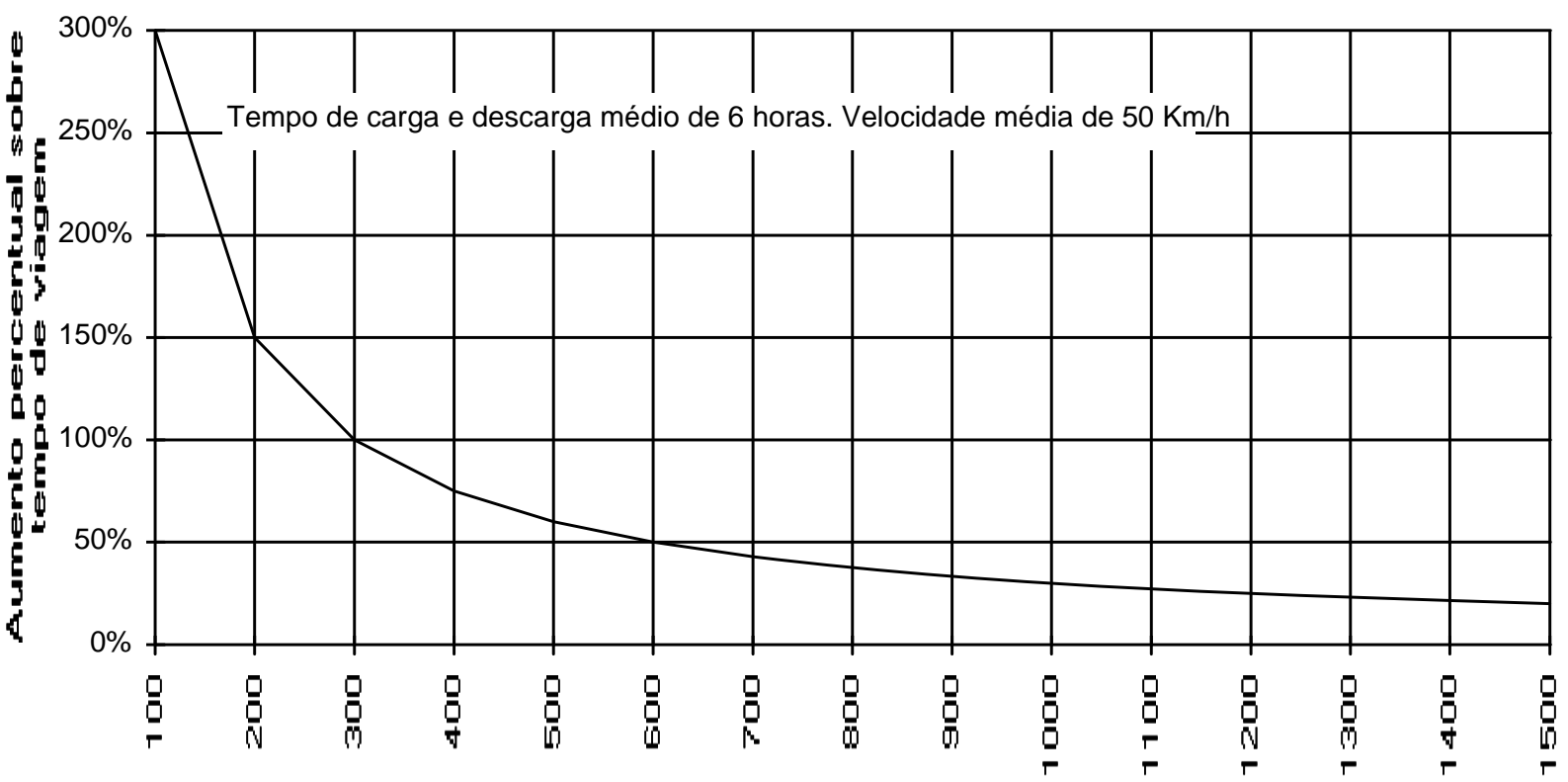

Distância da rota em Km

Figura 2 - Impacto do tempo de carga e descarga (média 6 horas) sobre o custo do frete

A título de exemplo, para uma rota média de $500 \mathrm{Km}$, velocidade média de $50 \mathrm{Km} / \mathrm{h}$ e tempos de carregamento e descarregamento totalizando 6 horas, o custo do frete seria de $\mathrm{R} \$ 575,00$ (exclusive despesas administrativas).

Realizando diversas simulações, com base no que foi descrito na seção anterior, foi possível determinar a participação do tempo de carregamento e descarregamento como percentual do custo de frete, considerando três tipos de rotas principais: curtas (100 Km), médias $(500 \mathrm{Km})$ e longas (1000 $\mathrm{Km})$. A figura 3 nos mostra que: as rotas curtas são extremamente penalizadas, pois o tempo de carregamento e de descarregamento respondem a quase $64 \%$ de seu custo total.

as rotas longas não apresentam um impacto tão grande, visto que o custo da espera para carregamento e descarregamento é diluído por um tempo de viagem proporcionalmente maior. Para uma rota de $1000 \mathrm{Km}$ o percentual deste custo mal passa de $15 \%$.

Para a rota padrão de $500 \mathrm{Km}$, o custo de carregamento e descarregamento corresponde a $26,10 \%$ do custo total, ou aproximadamente $\mathrm{R} \$ 150,00$ de um total de $\mathrm{R} \$ 575,00$. 


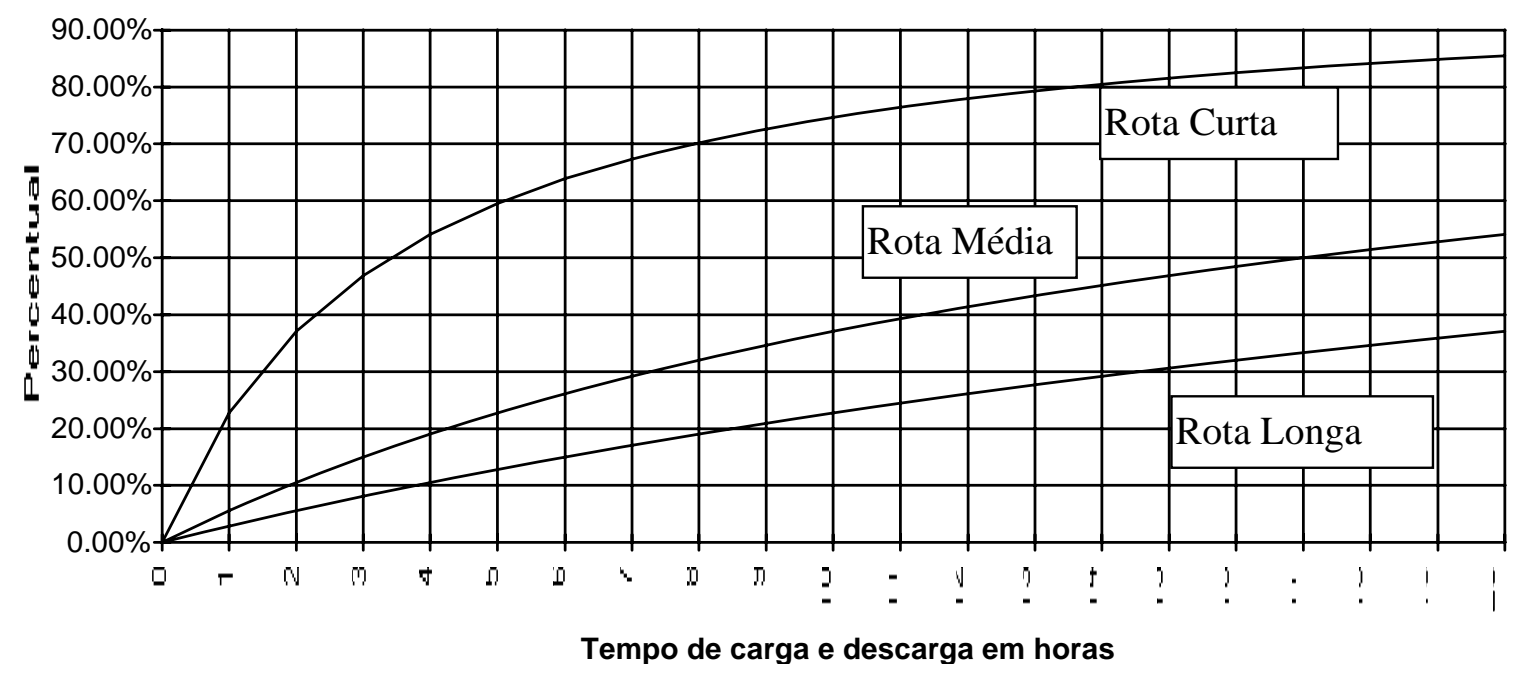

Figura 3 - Participação do tempo de carga e descarga (média 6 horas) no custo do frete comparativo para rotas curtas, médias e longas

Os ganhos potenciais de uma maior coordenação das atividades de carregamento e descarregamento, por outro lado, são visualizados na figura 4, sendo possível verificar: para rotas curtas, variações de $50 \%$ no tempo total de carregamento e descarregamento implicam em variações de $32 \%$ no custo do frete.

para rotas longas, variações desta magnitude no tempo total de carregamento e descarregamento implicam em variações de 7,5 \% no custo do frete. para a rota padrão de $500 \mathrm{Km}$, uma redução de $50 \%$ neste tempo implica numa redução de R\$ 75,00 (13,05\%) sobre o custo do frete. Em outras palavras, uma empresa de grande porte, que tenha uma necessidade de 1500 viagens por mês em rotas do tipo padrão, economizaria ao final de um ano o equivalente a R\$ 1.350.000,00 coordenando melhor as atividades de carregamento e descarregamento com seus clientes e transportadoras.

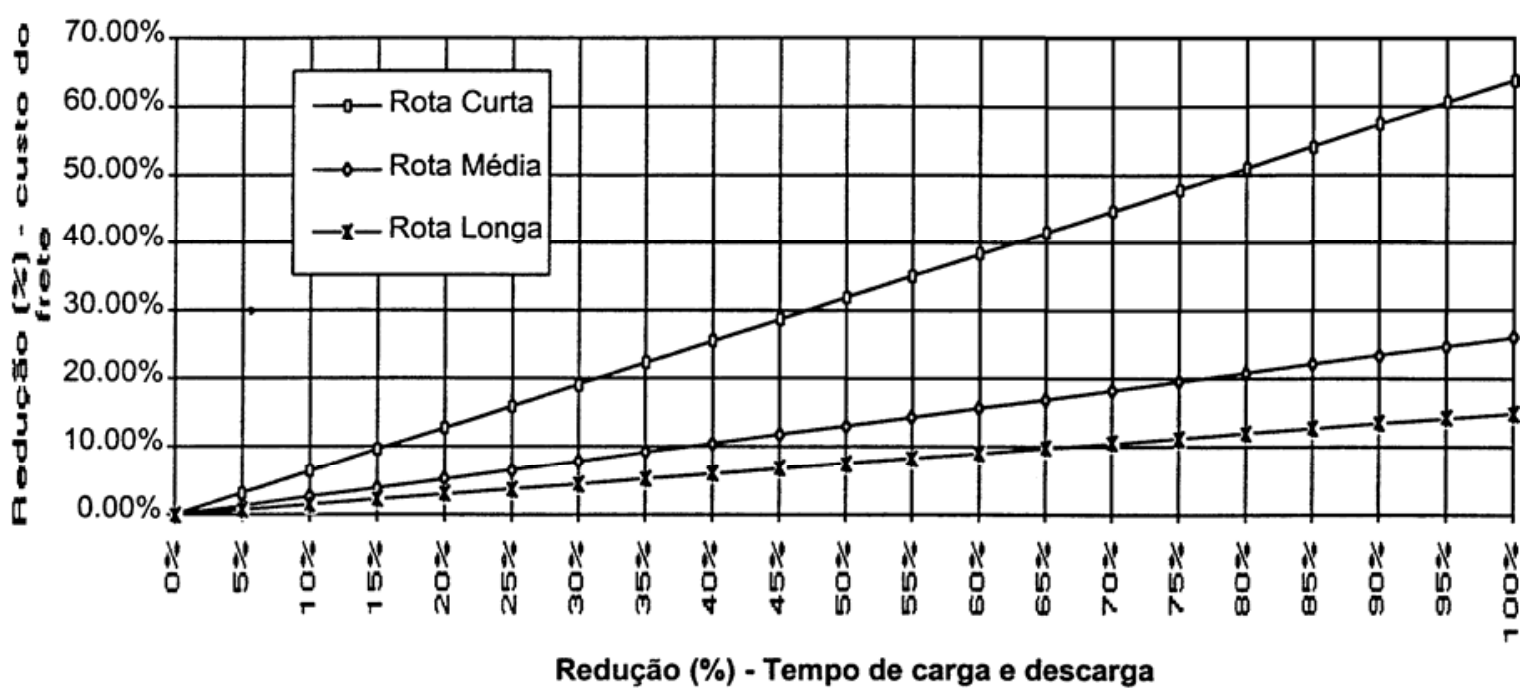

Figura 4 - Impacto da redução do tempo de carga e descarga (média 6 horas) sobre o custo do frete 


\subsection{Participação Percentual dos Diversos Tipos de Custo}

Nesta seção apresentamos a participação percentual dos diversos tipos de custo (fixos, variáveis, despesas administrativas e carregamento e descarregamento) sobre o custo total das rotas curtas, médias e longas.

O gráfico a seguir revela que o custo variável cresce em ritmo decrescente à medida que aumenta o tamanho das rotas, ao passo que o custo de carregamento e descarrega- mento possui maior impacto sobre as rotas mais curtas. Isto ocorre por que quanto mais longa a rota, maior a participação do custo variável sobre o custo total. Por outro lado, o custo de carregamento e descarregamento torna-se mais importante quanto maior for a razão entre o tempo consumido com o carregamento, o descarregamento e o tempo de viagem, que é característico das rotas curtas.

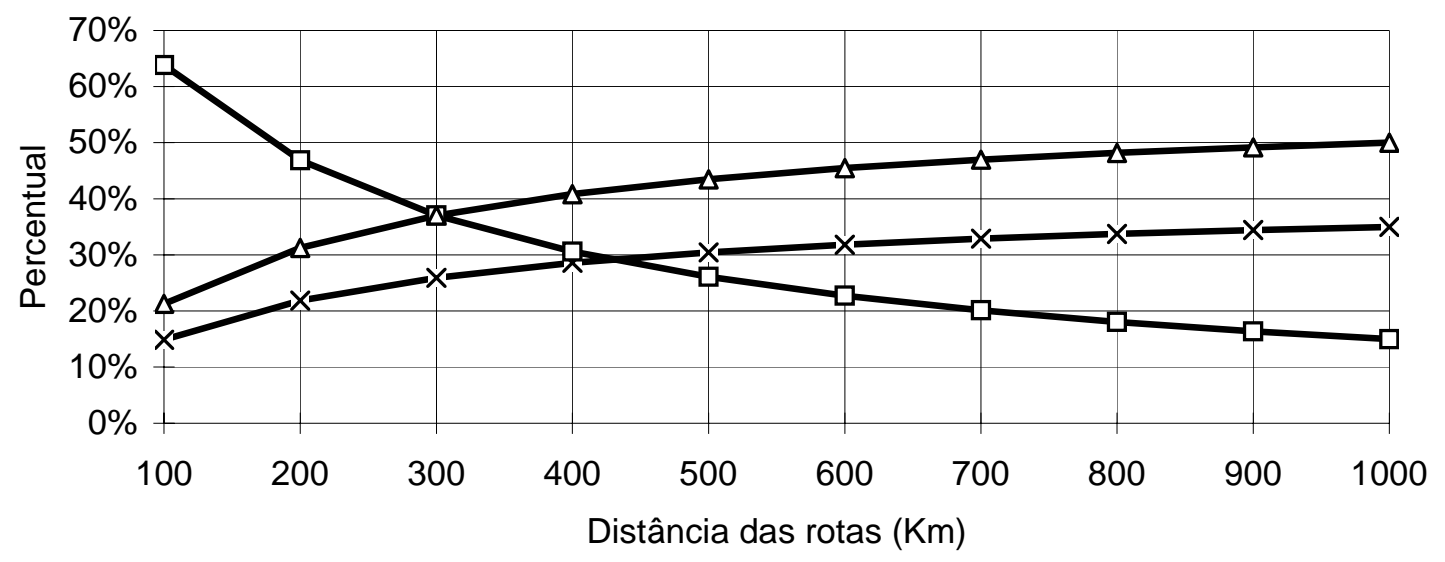

$-x-$ Custos Variáveis

$\rightarrow-$ Demais Custos Fixos Diretos e Indiretos

Figura 5 - Participação dos tipos de custo em função da distância

Antes de prosseguir, é importante ressaltar que a exploração destas oportunidades de ganhos só é possível com um novo padrão de negociação que envolva todos os elos do canal. Novamente GIBSON (1993) observa que ao ser abandonada a tradicional negociação baseada no poder, substituindo-a por uma estrutura racional e consensual de análise conjunta de custos, determinação de preços e compartilhamento de lucros, os relacionamentos antagônicos cedem espaço a relações cooperativas. Definir, então, a participação e os ganhos financeiros de cada parceiro, sobretudo o transportador, é o objeto de análise da próxima seção.

\section{Definindo a Margem de Cada Parceiro}

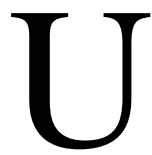
$m$ dos fatores que certamente motiva as transportadoras a buscarem parcerias com seus contratantes é a possibilidade de aumentar a produtividade de seu capital fixo (cavalos, baús, etc.) com a geração de um volume de frete estável ao longo do tempo. Uma medida financeira do grau de utilização dos recursos de uma empresa é o Retorno Sobre o Investimento (RSI), que é a razão entre o lucro Líquido e o investimento (capital) realizado para gerá-lo: 


$$
\begin{gathered}
\text { RSI = lucro líquido/investimento } \\
\text { ou } \\
\text { RSI = (lucro líquido/receita)x(receita/investimento) }
\end{gathered}
$$

Desta forma, vemos que o RSI pode ser descrito como o produto de duas razões: a primeira delas representando a margem ou o mark-up, e a segunda representando o giro do capital (grau de utilização do investimento). Sendo assim, a maioria das transportadoras vai dar mais atenção à margem embutida no preço do frete que ao grau de utilização de sua frota. Parcerias permitem, portanto, o estabelecimento de margens mais baixas sobre o custo de frete com uma contrapartida no volume de viagens (CHRISTOPHER, 1992). A figura 6 ilustra esta afirmação:

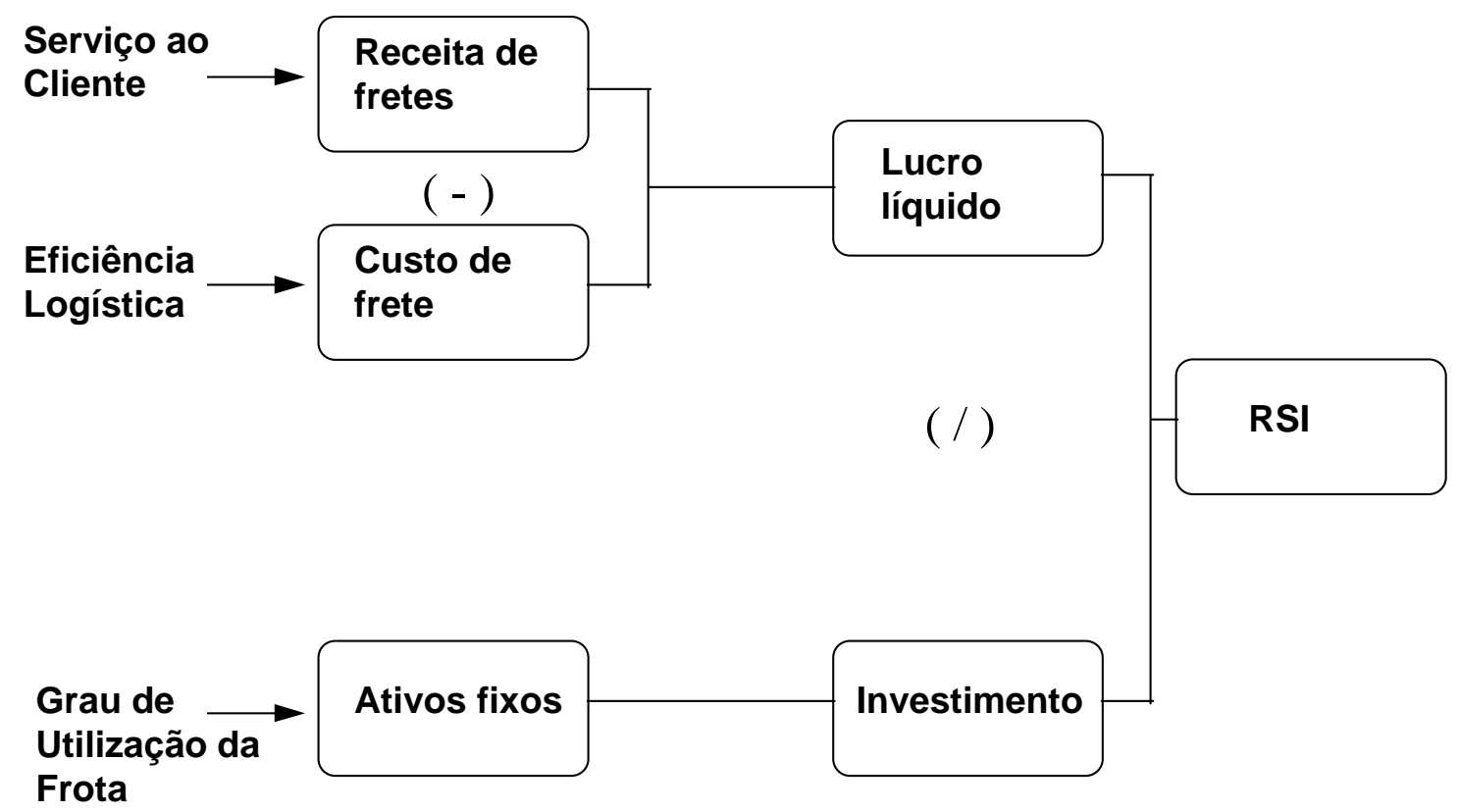

Figura 6 - Retorno sobre o investimento como função dos níveis de serviço ao cliente, eficiência do transporte e grau de utilização da frota

A figura 7, por sua vez, ilustra o comportamento da margem como função do número anual de viagens para a rota padrão tomada anteriormente como exemplo, buscando-se garantir ao transportador um retorno de $12 \%$ a.a. sobre seu investimento. Para efeitos de simplificação no cálculo do RSI, considerase este retorno de $12 \%$ a.a. antes do custo de capital utilizado como padrão na indústria brasileira. Para maiores detalhes, verificar planilha sugerida pela ANTC (Associação Nacional dos Transportadores de Carga). 


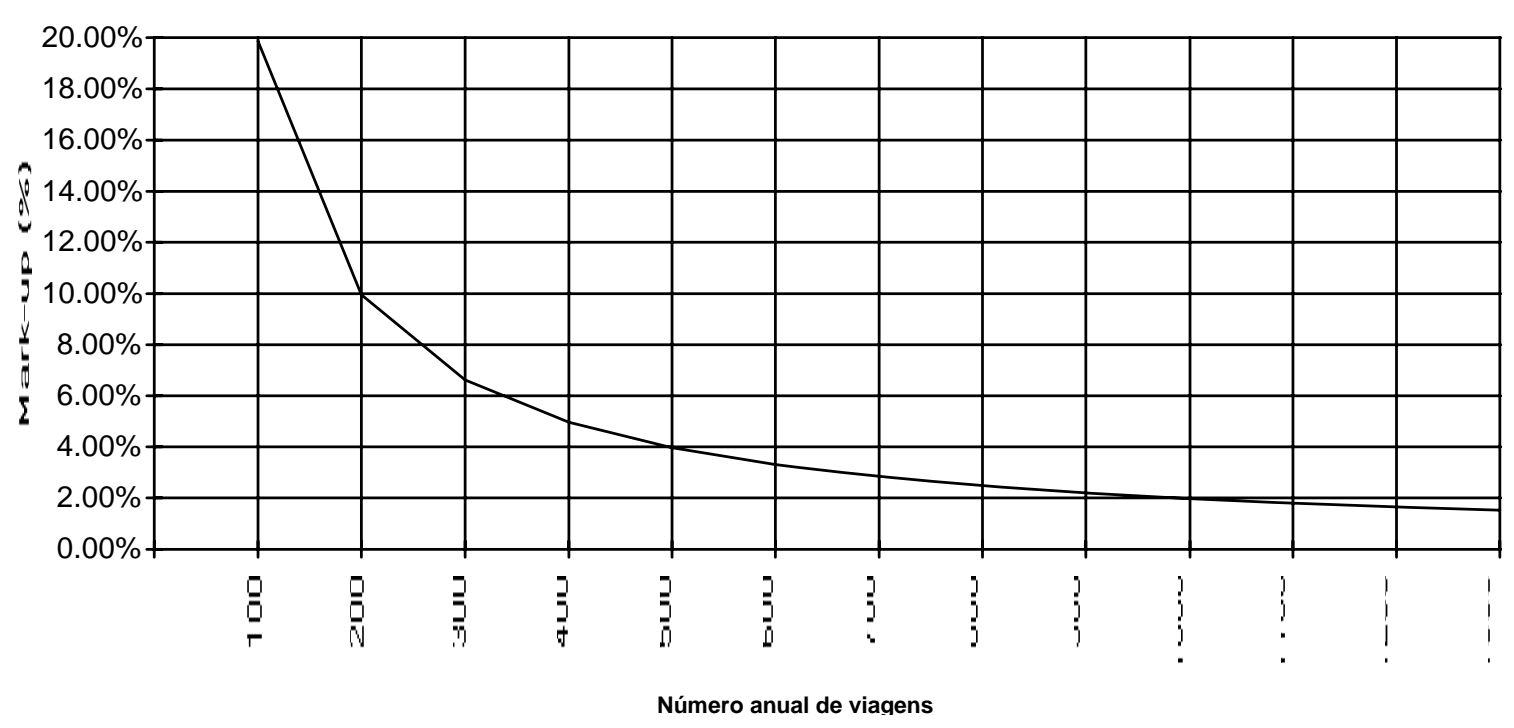

Figura 7 - Mark-up como função do grau de utilização da frota (RSI = 12\% a.a.)

\section{Conclusões}

A base para um programa conjunto de qualidade e produtividade no transporte, dentro do contexto de parcerias visto anteriormente, reside numa avaliação inicial da estrutura organizacional, procedimentos e tecnologias existentes entre os diversos membros da cadeia de suprimento. Entendendo claramente estas três dimensões, identificam-se facilmente as etapas críticas da atividade de transporte passíveis de melhoria.

A dimensão organizacional deve ser avaliada sob duas óticas distintas: uma perspectiva interna à empresa que está contratando o serviço de transporte e outra externa, que engloba fornecedores, clientes e transportadores. A perspectiva interna está focada no grau de organização dos processos logísticos dentro da empresa, de modo a determinar quais funções serão responsáveis pelo contato com transportadores e clientes, programação de entregas, remediação de falhas, etc. Já a perspectiva externa revela o grau de confiabilidade e formalização existente nos canais de comunicação entre as empresas da cadeia. É neste ponto que devem ser confrontadas informações sobre programação de entregas, disponibilidade de carretas e eventuais congestionamentos no cliente.

Os procedimentos, por sua vez, estabelecem métodos claros para coordenar a atividade de transporte em circunstâncias normais ou não, direcionando o esforço e a atenção dos gestores logísticos da cadeia. Por exemplo, a decisão de enviar carga a um cliente só após a verificação de seu grau de congestionamento para descarregamento e suas janelas de tempo para recepção é um procedimento que evita a retenção de veículos no cliente e tempos de descarregamento excessivos. Por outro lado, a decisão de um cliente em priorizar o descarregamento de veículos oriundos do fornecedor com recursos específicos (empilhadeiras, docas, etc.) também se constitui num exemplo de procedimento.

Finalmente, a tecnologia disponível determina a configuração básica de funcionamento e do fluxo de informações no sistema. O funcionamento é caracterizado por diversas variáveis como por exemplo o grau de paletização e automação das atividades de carregamento e descarregamento, 
emprego de equipamentos de rádio-freqüência, etc. Já o fluxo de informações pode ser alavancado por sofisticados sistemas de tracking ou rastreamento de veículos, auxiliando a programação e expedição de veículos bem como a monitoração de desempenho das etapas do transporte.

De qualquer forma, os elevados tempos para carregamento e descarregamento têm duas causas fundamentais:

Baixa capacidade de carregamento/descarregamento (origem tecnológica e/ou de procedimento). Esta capacidade pode ser medida em carretas/dia ou carretas/hora e é função de como são utilizados os principais recursos necessários a execução do carregamento/descarregamento: docas, empilhadeiras, operadores, etc. Nosso levantamento revelou que as instalações mais eficientes (tempos já deduzidos de esperas por burocracia, má coordenação, etc.) são aquelas que destinam docas exclusivas, bem como não compartilham empilhadeiras com a alimentação de linhas de produção ou com a arrumação das ruas num armazém. $\mathrm{O}$ aumento da capacidade de descarregamento passa, portanto, pelo investimento em novas docas, empilhadeiras e operadores.

Existem duas maneiras básicas para efetuar este tipo de investimento, passando necessariamente pelo conceito de parceria entre fornecedor-cliente. $\mathrm{Na}$ primeira, busca-se associar reduções na tarifa de frete a ganhos na eficiência da operação de carregamento. Na segunda, o próprio embarcador investe em recursos no cliente.

Ausência de canais de comunicação diretos entre os elos da cadeia (origem organizacional e/ou procedimento). $\mathrm{O}$ estabelecimento deste tipo de canal, bem como do tipo de informações a ser triangulado entre produtor, transportador e cliente permitem uma maior e mais efetiva coordenação do fluxo de informações e a realização de uma programação diária de entregas factíveis com a capacidade de descarregamento dos clientes.

Percebe-se, portanto, que dependendo do tipo de problema, seja ele organizacional, tecnológico, ou de procedimentos, há uma série de medidas básicas que podem ser tomadas para redução de desperdícios (elevados tempos de carregamento e descarregamento) no transporte entre os elos de uma cadeia de suprimentos. A adoção destas medidas paralelamente ao acordo quanto a um sistema de custeio de frete com as transportadoras, constitui um primeiro passo à implementação de um programa de qualidade e produtividade no transporte dentro do contexto de parceria logística. Finalmente, neste contexto, as oportunidades para exploração de ganhos de cada parceiro devem ser claras e facilmente mensuráveis, algo extremamente facilitado pelo sistema de custeio descrito anteriormente.

\section{Referências Bibliográficas:}

BALLOU, R.H.: Logística Empresarial - Transportes, Administração de Materiais, Distribuição Física, Atlas, São Paulo, 1993.

BOWERSOX, D.J.: "The Strategic Benefits of Logistics Alliances”. Harvard Business Review, July-August, p. 36-45, 1990.
BOWERSOX, D.J. \& CLOSS, D.J.: Logistical Management: a Systems Integration of Physical Distribution, Manufacturing Support and Materials Procurement, MacMillan, New York,

CHRAGFOPHER, M.: Logistics and Supply Chain Management-Strategies for Reducing Costs and Improving Services, Pitman Publishing, UK, 1992. 
COOPER, R. \& KAPLAN, R.: The Design of Cost Management Systems, Prentice-Hall, 1991.

ELLRAM, L. \& LA LONDE, B.J.: "Understanding the Implications of Activity-Based Costing for Logistics Management”. Annual Conference Proceedings, Council of Logistics Management, p. 11-25, 1994.

GARDNER, J.T. \& COOPER, M.C.: "Understanding Shipper-Carrier and ShipperWarehouser Relationships: Partnerships Revisited”. Journal of Business Logistics, 15(2), p.121-143, 1994.

GIBSON, B.J. \& SINK, H.L.: "Shipper-Carrier Relationships and Carrier Selection Criteria”. The Logistics and Transportation Review, 29(4), p.371-382, 1993.
HOPKINS, S.A. \& STRASSER, S.: "Service Quality Gaps in the Transportation Industry: an Empirical Investigation”. Journal of Business Logistics, 14(1), p.145-160, 1993.

KANTER, R.M.: “Collaborative Advantage”. Harvard Business Review, July-August, p.96-108, 1994.

LA LONDE, B.J. \& COOPER, M.C.: Partnerships in Providing Customer Service - A Thrid Party Perspective; Council of Logistics Management, Illinois, 1989.

LANDEROS, R.\& RECK, R.: "Maintaining Buyer-Supplier Partnerships". International Journal of Purchasing and Materials Management, Summer, p.3-11, 1995.

PARASURAMAN, A. \& BERRY, L.: "SERVQUAL: A Multiple-Item Scale for Measuring Consumer Perceptions of Service Quality”. Journal of Retailing, 64, Spring, p.1241, 1988.

\section{SEEKING EFFECTIVENESS IN THIRD-PARTY TRANSPORTATION: COST STRUCTURES, PARTNERSHIPS AND INCREASED EFFICIENCIES}

\section{Abstract}

The main objective of this paper is to present a rational model for cost allocation in the transportation activity as a key element for designing and maintaining partnerships between shippers and carriers. The utilization of the proposed cost allocation model for a real case situation gave rise to several conclusions. The most important of them is the fact that the cost allocation system currently used by Brazilian shippers and carriers underestimate the cost of short routes and overestimate the longer ones. This is mainly due to high levels of inefficiency in transportation, most of them observed in the operations of loading and unloading, which take six hours on average.

Based on the above issue, the paper explores the development of the concept of partnership between shippers and carriers. The adoption of a productivity and quality program which includes an agreement between shippers and carriers over a common cost allocation system, provides several metrics on cost, efficiency and productivity that help to improve loading and unloading operations.

The paper concludes with the description of the main causes that affect efficiency on transportation in Brazil: organization, procedures and technologies. 